\title{
Beard reconstruction using hair grafts in a free flap
}

\author{
Andre Y Levesque MD, Benjamin J Schalet MD, James L Dolph MD
}

AY Levesque, BJ Schalet, JL Dolph. Beard reconstruction using hair grafts in a free flap. Can J Plast Surg 2011;19(4):151-152.

Hair transplantation using micrografts or minigrafts is a standard procedure used for hair restoration in androgenic, burn scar and cicatricial alopecia. These grafts have also been used to reconstruct the eyebrow, eyelash, mustache, beard and pubic escutcheon. A patient who underwent successful micrograft and minigraft hair transplantation into a free osteocutaneous mandibular flap reconstruction is presented. The patient was very satisfied with his reconstruction, and the hair transplants provided excellent camouflage for the flap.

Key Words: Free tissue transfer; Hair transplantation

$\mathrm{H}$ ead and neck cancer treatment frequently requires reconstruction using free tissue transfer for large defects. Even with careful planning and attention to an aesthetic reconstruction, patients often believe that their postoperative appearance is significantly altered. Ideal reconstructions achieve a normal appearance at conversational distance, facial balance and symmetry, inconspicuous scarring and dynamic facial expression. For male patients, the loss of facial hair can be of concern. In addition, postoperative scarring and skin appearance can create a visual focal point at the site of the reconstruction.

Micro- and minigrafts for hair restoration have become the standard of care in the treatment of male pattern baldness (1-3). They have also been described for reconstruction of hair-bearing areas outside of the scalp including eyebrow, eyelash, mustache and beard reconstruction, as well as reconstruction of the pubic escutcheon $(4,5)$. Micro- and minigrafts have been successfully used in areas of scarring and in nonhair-bearing skin. Common indications for microand minigrafting include burn scar alopecia and postsurgical cicatricial alopecia.

We describe a case of micro- and minigraft hair transplantation for beard restoration after free flap reconstruction for head and neck cancer involving the mandible and chin. No deviation from standard techniques of hair transplantation was required. The reconstructed flap supported the transplanted follicles. Two sessions of grafting using a total of 200 follicles per session were required for the desired density. The patient did well postoperatively and was extremely satisfied with the results.

\section{CASE PRESENTATION}

The patient was a 56-year-old man who was diagnosed with stage T4NOMx squamous cell carcinoma at 42 years of age. He underwent wide excision of the floor of his mouth and chin with a hemimandibulectomy, left modified radical neck dissection, and right submandibular triangle dissection with immediate free fibula reconstruction. His fibula free flap failed, requiring debridement, and was followed by reconstruction with pedicled pectoralis myocutaneous flap and reconstruction plate. This ultimately resulted in an exposed reconstruction plate and wound breakdown, which was then reconstructed using a free iliac crest osteocutaneous flap. This achieved stable

\section{La reconstruction d'une barbe au moyen de greffes de cheveux sur un lambeau libre}

La greffe de cheveux au moyen de microgreffes ou de minigreffes est une intervention standard pour régénérer les cheveux sur des cicatrices de brûlures ou une alopécie cicatricielle d'origine androgène. Ces greffes permettent également de régénérer les sourcils, les cils, la moustache, la barbe et des plaques de la région pubienne. Les auteurs présentent le cas d'un patient qui a subi une microgreffe et une minigreffe réussies de cheveux sur la reconstruction d'un lambeau mandibulaire ostéocutané libre. Le patient s'est révélé très satisfait de la reconstruction, et la greffe de cheveux a permis de camoufler le lambeau à merveille.

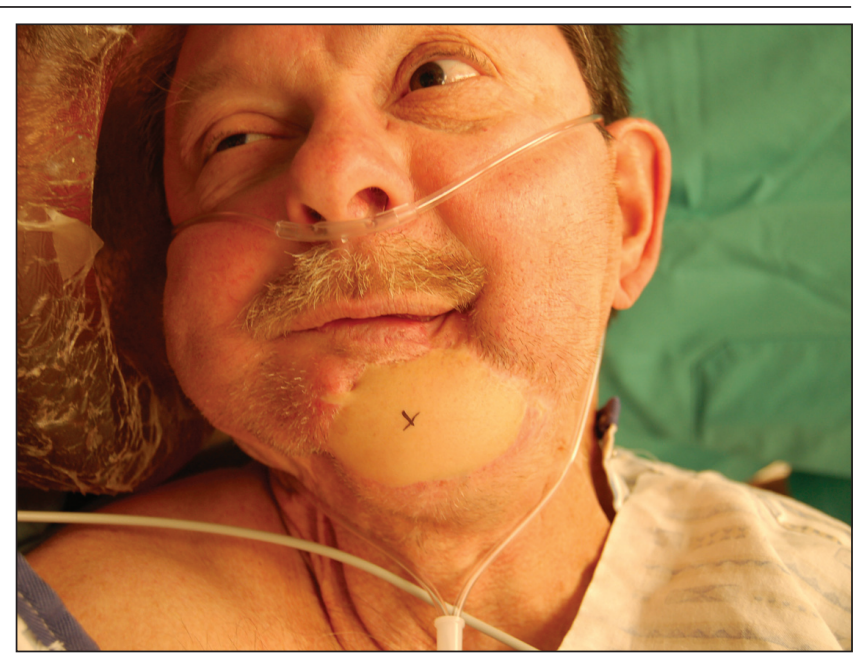

Figure 1) Patient with stable coverage of an extraoral, intraoral and mandibular defect with free iliac crest osteocutaneous flap. The hairless cutaneous paddle is demonstrated

coverage for his mandibular and intra- and extraoral defects. He underwent three other minor tissue rearrangements and flap debulking procedures over the years. Overall, he was satisfied with his result, but believed that the white, hairless, cutaneous external paddle was an unsightly focal point. On discussion, it was decided that beard reconstruction would potentially help. Figure 1 shows his stable, 11-year reconstruction using the iliac crest osteocutaneous flap, before hair transplantation. He underwent two separate sessions of 200 follicular unit micro- and minigrafting to the free flap, separated by 11 months. Figure 2 is an intraoperative photograph of micro- and minigrafting into the free osteocutaneous flap. Beard hair angulation and distribution were observed and mimicked. He has achieved stable results and is very satisfied with his result. Figures 3 and 4 are postoperative photographs two years following the second session of hair transplantation.

\section{Albany Medical Center and Sam Stratton Veteran's Affairs Hospital, Albany, New York, USA}

Correspondence: Dr Andre Y Levesque, Division of Plastic Surgery, Albany Medical Center and Sam Stratton Veteran's Affairs Hospital, MC-61, 43-47 New Scotland Avenue, Albany, New York 12208, USA. Telephone 518-262-2229, fax 518-262-5692, e-mail LevesqA1@amc.edu 


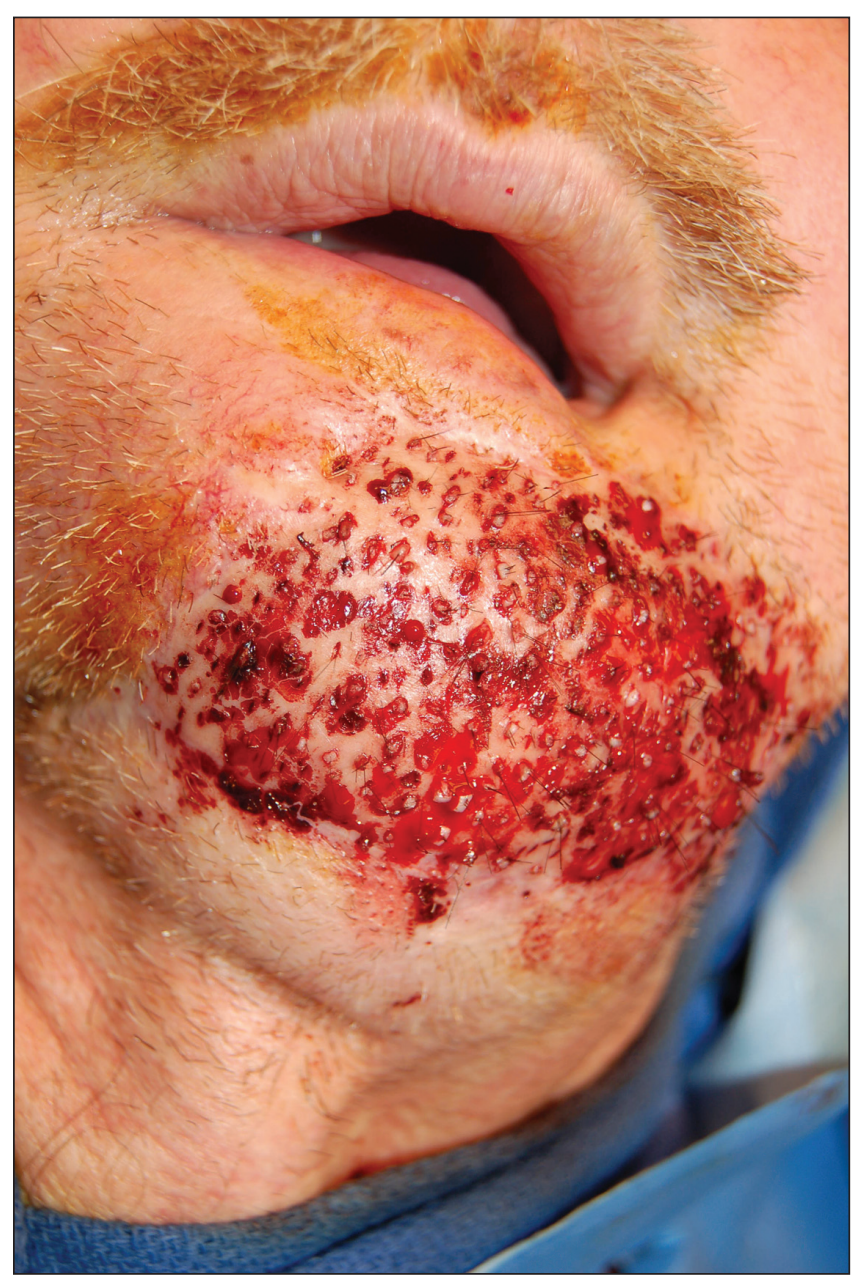

Figure 2) Intraoperative appearance of micro- and minigraft hair transplantation into osteocutaneous flap

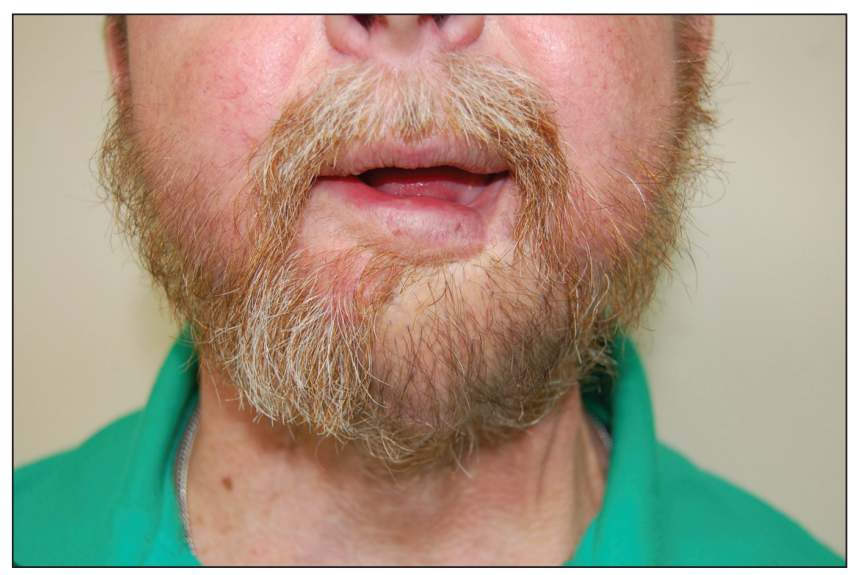

Figure 3) Two-year postoperative appearance of hair transplantation into the osteocutaneous flap (frontal view)

\section{DISCUSSION}

The use of micro- and minigraft hair transplantation is safe in free flap skin paddles. Good aesthetic outcomes can be achieved, with a

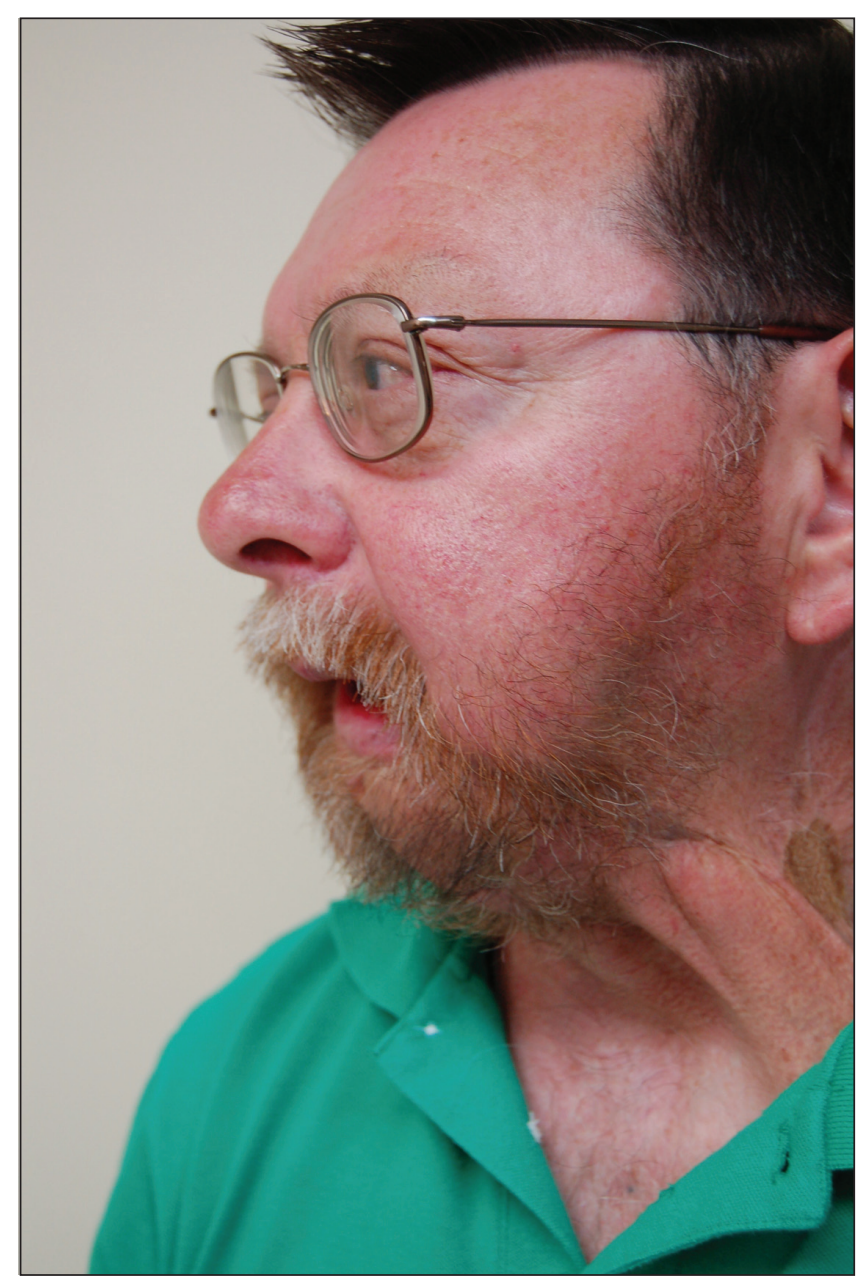

Figure 4) Two-year postoperative appearance of hair transplantation into the osteocutaneous flap (side view)

realistic beard appearance and excellent camouflage of the surgical scars and flaps. Patient satisfaction is high. For patients who desire a beard, this is a time-consuming but effective method for reconstruction.

DISCLOSURE: The Institutional Review Board at the Sam Stratton Veteran's Affairs Hospital (New York, USA) reviewed the manuscript and approved its publication. The patient has consented for the use of photographs shown.

\section{REFERENCES}

1. Barrera A. The use of micrografts and minigrafts in the aesthetic reconstruction of the face and scalp. Plast Reconstr Surg 2003;112:883-90.

2. Rawnsley JD. Hair restoration. Facial Plast Surg Clin North Am 2008;16:289-97.

3. Konior RJ. Advances in surgical hair restoration. Facial Plast Surg 1993;9:37-48.

4. Gandelman M, Epstein JS. Hair transplantation to the eyebrow, eyelashes, and other parts of the body. Facial Plast Surg Clin North Am 2004;12:253-61.

5. Sahinoglu K, Ergün SS. Follicular unit transplantation: The option of beard construction in eunuchoid men. Dermatol Surg 2002;28:866-8. 